\title{
CONTRATO POR ADESÃO: UMA CONSTRUÇÃO DIALÉTICA*
}

João Paulo S. de Siqueira** Recibido: Septiembre 16 de 2016 Aprobado: Diciembre 1 de 2016

\section{RESUMO}

A presente pesquisa é regida pela perspectiva de interdisciplinaridade, analisa o contrato por adesão não como um instituto estritamente jurídico, mas também e principalmente como um elemento histórico, econômico e social. A investigação objetiva questionar e entender de que maneira essa forma de contratação, imprescindível em uma sociedade de consumo massificado, representa um elemento dialético e impositivo de interesses econômicos. A pesquisa orienta-se pelo método histórico dialético, busca o entendimento da questão além de sua aparência formal e imediata, objetiva apreender e compreender a essência da relação social fornecedor-consumidor mediada pelo contrato por adesão. O estudo resultará numa relevante contribuição no entendimento da atuação e da significação dessa forma de contratação na sociedade de consumo contemporânea.

Palavras - Chave: Contrato por Adesão, Consumo, Dialética.

\section{ADHESION CONTRACT: A DIALECTIC CONSTRUCTION}

\footnotetext{
ABSTRACT

This investigation is guided by the interdisciplinary perspective, analyzes the adhesion contract not as a strictly legal institution, but also

* La presente investigación corresponde a un trabajo de reflexión, derivada de pesquisa realizada en la maestría en consumo y desarrollo social en la Universidad Federal Rural de Pernambuco.

** Graduado en Derecho por la Universidad Católica de Pernambuco (Brasil). Especialista en Derecho del Estado por la Universidad Anhanguera (Brasil). Magister en Consumo, Cotidiano y Desarrollo Social por la Universidad Federal Rural de Pernambuco (Brasil). Alumno Regular de los cursos para el Doctorado en Derecho Civil en la Universidad de Buenos Aires (Argentina). Abogado, Profesor y Pesquisador. Correo electrónico: jpssiqueira@yahoo.com.br
} 
and mainly as a historical, economic and social element. The investigation aims to question and understand how this form of agreement, essential in a mass consumption society, represents a dialectical and taxing element of economic interests. The research is orientated by the historical - dialectic method, seeks the understanding of the issue beyond its formal and immediate appearance objective, understand the essence of social relationship consumer - supplier mediated by the adhesion contract. The study will result in an important contribution to understand the role and significance of this form of contracting in the contemporary consumption society.

Keywords: Adhesion Contract, consumption, dialectics.

\section{CONTRATO POR ADHESIÓN: UNA CONSTRUCCIÓN DIALÉCTICA}

\section{RESUMEN}

La presente investigación está orientada por la perspectiva de la interdisciplinariedad, analiza el contrato por adhesión no como un instituto estrictamente jurídico, sino también y principalmente como un elemento histórico, económico y social. La investigación tiene como objetivo cuestionar y entender de qué manera esa forma de contratación, imprescindible en una sociedad de consumo masificado, representa un elemento dialectico e impositivo de intereses económicos. La investigación se orienta por el método histórico - dialéctico, busca la compresión de la cuestión más allá de su apariencia formal e inmediata y objetiva, aprender y comprender la esencia de la relación social proveedor-consumidor, mediada por el contrato por adhesión. El estudio resultará en un relevante aporte en la comprensión del rol y significado de esta forma de contratación en la sociedad de consumo contemporánea.

Palabras clave: Contrato por Adhesión, Consumo, Dialéctica.

\section{INTRODUÇÃO}

Nossa sociedade contemporânea mostra-se globalizada, plural, dinâmica e dialética. Nela, o consumo assume um papel fundamental e estruturante, direciona e interage com incontáveis elementos e arestas. Dessa maneira, prevalece o entendimento, tanto no senso comum como 
no meio científico, que vivemos numa sociedade do consumo, na era do capitalismo da maturidade ou tardio, como assevera Ernest Mandel (1982).

O consumo deixou de ser um tema limitado a restritas e específicas áreas do conhecimento, hoje constitui um fator de estruturação e direcionamento social, tornando-se uma metadisciplina ${ }^{1}$, presente, atuante e também dependente de múltiplos campos do saber, é o que confirma o Teorema de Godel ao determinar que "não existe sistema formal de conhecimento que contenha em si mesmo a sua norma de não contradição" (apud GHELEN, 2005, p.22).

Diante desse panorama, inseridos numa sociedade complexa e contraditória, que assume a forma de sociedade de consumo (BAUDRILLARD, 1995), indo mais além, de um consumo massificado, generalizado e globalizado, na qual tudo é transformado em mercadoria e onde quase tudo é adquirido e acessado através de uma contratação, peça fundamental dessa engrenagem é o contrato por adesão.

Instrumento negocial imprescindível em um contexto social de consumo massificado, e que não pode ser entendido como um elemento estritamente legal e jurídico, vai muito além, mostra-se como uma construção histórica, humana e social, sendo uma expressão da dialética das relações capitalistas de troca e consumo na sociedade contemporânea.

Todavia, o modo como esse contrato se configura e é apresentado aos consumidores é camuflado e dicotômico, parece ser um elemento secundário e irrelevante ou até mesmo inexistente quando, em realidade, representa um componente fundamental e significativo da mercadoria e das relações de troca em uma sociedade de consumo massificado.

Indo mais além, quando percebido é apenas compreendido como um mero elemento jurídico e alheio à realidade negocial e mercantil, comportamento que se mostra perigoso, pois a sociedade e todas as suas interações e relações são ativas e ressignificadas a todo tempo.

Os desafios da compreensão desse processo estimulam pesquisas que objetivam entender de que maneira o contrato por adesão, elemento não

1 A terminologia 'metadisciplina' é uma alusão ao termo "metaética", apresentado por Eduardo Tinant em sua obra "Bioética jurídica, dignidad de la persona y derechos humanos". Ao utilizá-la, pretendemos mostrar que o conhecimento científico ultrapassa as arestas disciplinares rígidas e busca sua fundamentação em diversos e plurais modos de entender o mundo. 
estritamente jurídico, mas também econômico e social, atua, interfere, direciona e estimula as práticas de consumo em nossa sociedade contemporânea. Daí o propósito de compreender o modo pelo qual esse instrumento legal transforma-se num elemento relevante do consumo social e massificado, apto a promover realizações pessoais e sociais nos/nas consumidores/as.

\section{CONTRATO PORADESÃO}

A tradição clássica ${ }^{2}$ estabelecia que a relação contratual caracterizava-se como um negócio jurídico firmado entre partes em situação de igualdade e com liberdade para estabelecerem a forma e o conteúdo daquele acordo de vontades ${ }^{3}$. Porém, as transformações sociais, jurídicas, produtivas e principalmente econômicas alteraram essa concepção contratual individualista e paritária.

A produção de bens aumentou, a noção de igualdade formal entre os contratantes foi superada, monopólios empresariais foram construídos e o consumo tornou-se massificado, fatores que impuseram ao Direito a necessidade de apresentar um instrumento capaz de reger essa nova realidade.

Cientes que o Direito é também e principalmente uma construção humana, portanto histórica, o Ordenamento Jurídico, para dar respostas, possibilidades e soluções adequadas a essa nova realidade capitalista, produtiva e consumista, apresenta uma nova espécie de contratação, homogênea, célere, impessoal e capaz de abarcar as necessidades da vida moderna e dos interesses produtivos e consumistas. São os contratos por adesão, explicados por Cláudia de Lima Marques:

Na sociedade de consumo, com seu sistema de produção e de distribuição em grande quantidade, o comércio se despersonalizou e os métodos de contratação em massa, ou estandardizados, predominam em quase todas as relações contratuais entre empresas e consumidores, neste contexto, destacam-se os contratos de adesão. (MARQUES, 2012, p.50).

2 Essa teoria contratual foi proposta e aceita pelo Estado Liberal diante de seus preceitos de liberdade individual e livre iniciativa, que posteriormente foi complementada e substituída pelas ideias do Estado Social, embasadas pelos ideais de dignidade da pessoa humana e função social do contrato.

3 Importante lembrar que o acordo de vontades, declaradas e convergentes (consensualismo) é o principal elemento constitutivo do contrato para a teoria de formação contratual da tradição jurídica europeia continental, que influencia e conduz os ordenamentos jurídicos latino americanos. 
A Revolução Industrial e a introdução da máquina ao processo produtivo e posteriormente o surgimento da cadeia de montagem fordista, possibilitaram a fabricação de bens e mercadorias em série, o que trouxe como consequência a expansão e massificação da produção industrial de mercadorias, possibilitando o crescimento do mercado de consumo e a expansão cada vez maior das transações capitalistas de produção e as relações de trocas nacionais e internacionais, configurando-se, desta forma, a sociedade de consumo contemporânea.

Importante salientar que esse processo de desenvolvimento e expansão provocou a denominada demanda induzida, elemento que constitui mais uma característica da era da sociedade de consumo (BOUDRILLARD,1995; MANDEL, 1982), pois não são mais as necessidades humanas que determinam e direcionam a produção de bens.

O panorama foi invertido, novas necessidades são criadas pelo sistema produtivo, que determina previamente o que vai ser produzido e cria nos consumidores a "necessidade" de consumo desses bens. Representa o processo de produção, intercâmbio, distribuição e de consumo que também contribui para o surgimento e expansão do contrato por adesão como mais um elemento do capitalismo contemporâneo.

$\mathrm{O}$ arquétipo do contrato estabelecido pela teoria clássica, de uma contratação firmada entre partes iguais, elaborado de maneira paritária e recíproca, de cumprimento imediato, denominado de contrato perfeito, não representa o modelo contratual do mundo contemporâneo, configurado como uma era de consumo massificado.

Passa a vigorar uma quase total despersonalização nas relações de consumo, com novas formas de contratação, estandardizadas e massificadas, típicas da economia capitalista e que permitem a realização idêntica e simultânea de milhares de contratações.

As empresas sentiram a necessidade de vender com rapidez e em larga escala, e esta necessidade permitiu criar uma ferramenta (negocial e jurídica) que integrasse a mercadoria/bem e viabilizasse o consumo em massa das mesmas. Surge assim, nesse momento histórico do processo capitalista de produção o contrato por adesão.

A adesão como forma de validação das contratações tem suas raízes históricas no Direito Romano, evidente que sofreu alterações em sua 
estruturação ao longo da história e a forma que se apresenta hoje é totalmente distinta das perspectivas romanas. Dessa forma, importante ressaltar que o contrato por adesão, que será aqui analisado, é o que atua nas contratações na esfera do consumo massificado contemporâneo.

Neste breve trabalho, tratamos apenas das contratações por adesão no âmbito do Direito do Consumidor, dessa forma, não nos detemos nas contratações firmadas entre particulares, que também podem ser formalizadas por adesão, mas que não são a regra, pois normalmente essas relações são concretizadas através do contrato paritário, cujas cláusulas e estipulações são elaboradas de comum acordo ${ }^{4}$ entre as partes contratantes, havendo a possibilidade de convenção e deliberação acerca do conteúdo da negociação, atividades impensadas nas contratações por adesão.

É fundamental o esclarecimento que o contrato por adesão não é uma espécie contratual como a compra e venda, locação ou comodato, mas sim uma maneira de expressão da "vontade do contratante" para a efetivação e concretização da negociação, que se materializa contemporaneamente na transação livre de um bem/mercadoria.

Representa, em verdade, uma técnica de formação contratual, podendo ser aplicada em qualquer categoria de contrato, sempre que for desejada a rapidez em sua concretização e houver a possibilidade de imposição da vontade de uma das partes, podendo ser escrito (formal), verbal, oral, cibernético e até mesmo gestual.

É justamente o ato de aderir que tem o poder de transformar e definir uma negociação como um típico contrato por adesão, pois antes dessa etapa, o instrumento é apenas um contrato com cláusulas predispostas, tecnicamente não pode ainda ser chamado de contrato por adesão.

E torna-se relevante a análise dessa relação sob dois aspectos: o contrato predisposto e o contrato por adesão: a primeira trata da fase pré-negocial, ocorre com a elaboração das cláusulas que serão oferecidas ao público, mas ainda sem a aceitação do aderente, funcionando como uma proposta.

Já o contrato por adesão marca o momento de real celebração do negócio, pois é a partir daí que existe a relação jurídica bilateral, é o momento da

4 Esta espécie de contratação é denominada de "gré a gré" pelo Código Civil da província de Quebéc no Canadá, que mesmo sendo um país participante do Common Law possui estados que adotam os preceitos do Sistema Jurídico Francês, devido ao processo de colonização. 
"convergência de vontades", ou seja, a vontade do aderente acata a vontade já manifestada do proponente, em suma, são aspectos do mesmo fenômeno visualizados em momentos distintos.

A doutrina majoritária tem tratado as expressões de contrato predisposto, condições gerais dos contratos e contratos por adesão como expressões sinônimas do mesmo fenômeno, qual seja, o monopólio do conteúdo ou das cláusulas do negócio jurídico pela parte contratualmente mais forte. Como prosseguimento em nossa linha de raciocínio, é necessário apresentar uma conceituação do contrato. Evidente que temos a consciência que qualquer tentativa de elaboração de um conceito é tarefa complexa, pois traz consigo a visão de mundo e conceitos prévios, sobretudo quando tratamos de elementos humanos e sociais, que estão em constante processo de construção e significação.

Assim sendo, compreendemos o contrato por adesão como a contratação cujas cláusulas são preestabelecidas, redigidas e ditadas de forma unilateral por uma das partes (fornecedores e empresários/as), sem que a outra parte contratante (consumidores/as) possa discutir ou alterar substancialmente o conteúdo da contratação.

Cabe a esta, a mera aceitação (adesão) ao que foi disposto ou a não efetivação do contrato e consequentemente da negociação ali estabelecida. É a diretriz estabelecida pelo Código de Defesa do Consumidor brasileiro em seu artigo 54:

Contrato de adesão é aquele cujas cláusulas tenham sido aprovadas pela autoridade competente ou estabelecidas unilateralmente pelo fornecedor de produtos ou serviços, sem que o consumidor possa discutir ou modificar substancialmente seu conteúdo.

Já o Estatuto do Consumidor colombiano (Lei 1.480/2011) estabelece que "Contrato de adesão é aquele em que as cláusulas são predispostas pelo produtor ou provedor de serviços, de maneira que o consumidor não pode modificá-las, nem pode fazer outra coisa que aceitar ou recusar".

Nessa mesma linha de raciocínio, o Código Civil Italiano, em seu artigo 1341, enuncia o contrato por adesão como aquele em que "as cláusulas são predispostas por somente um dos contratantes, de maneira que o outro não pode modificá-las, nem pode fazer outra coisa senão aceitar o conteúdo ou recusar o contrato", ação que permitiria a posse, o uso e 
usufruto do bem/mercadoria. De maneira semelhante, Roberto Ruiz estabelece o seguinte conceito:

O contrato por adesão é aquele que é formado por cláusulas predeterminadas, elaboradas e redigidas por apenas uma das partes, carecendo o aderente da possibilidade de discutir ou modificar seu conteúdo. (RUIZ, 2012, p.185).

Para Joaquim de Souza Ribeiro, as contratações por adesão, de maneira contrária aos contratos paritários, perfeitos ou negociáveis, podem ser conceituadas como "a contratação efetivada pela conformação unilateral dos ditames de uma das partes, que exclui a autodeterminação do aderente, fundamentada pela disparidade do poder negocial" (RIBEIRO, 2007,p. 265).

No Capital, no capítulo terceiro, referente à mercadoria, Karl Marx (MARX, 2010), preconiza que a relação jurídica - leia-se o contrato - é uma relação de vontade (consentimento), o vínculo jurídico, em realidade, apenas reflete a relação econômica entre as partes que, numa sociedade capitalista de consumo massificado, normalmente estão em situações de ampla disparidade jurídica, econômica, cognitiva e social, daí a possibilidade de uma delas ter a prerrogativa e possibilidade de impor a outra os seus interesses. Dessa maneira, o contrato, em verdade, representa uma relação dialética entre classes e as diferentes frações e estratos sociais que as compõem.

Percebe-se que, nessas contratações, o negócio jurídico não é resultado de um real e efetivo acordo de vontades livremente firmado pelos contratantes, ideia fundamental do sentido de liberdade contratual, conceito jurídico que merece ser melhor explicado: Em termos técnicos, liberdade de contratar é a possibilidade, a autonomia de firmar, ou não, a negociação, já a liberdade contratual (autorregulação) é a possibilidade de construir paritariamente o conteúdo contratual.

Em realidade, o que existe é uma imposição unilateral da vontade e dos interesses de uma das partes sobre a outra, as vantagens do empresariado industrial, comercial, banqueiros e das grandes empresas privadas prestadoras de serviços, em termos nacionais e transnacionais, que tendem a promover uma uniformidade, igualação e despersonalização nas relações sociais de consumo, tornando os indivíduos anônimos, imersos na massa de consumidores/as. 
É uma estrutura de relações assimétricas, desiguais, contraditórias e daléticas, resultante da historia da formação das sociedades capitalistas, que na contemporaneidade globalizada, em que os avanços e inovações tecnológicas também se massificam, seus ciclos de crise tornam-se mais estruturais, originando essa complexa conjuntura jurídica, econômica, social e cultural, como ocorre nos dias atuais.

Em realidade, os contratos por adesão configuram-se e representam mais uma forma de imposição dos interesses do capital sobre os/as consumidores/as e sua autonomia volitiva. É a argumentação apresentada por Aníbal Alterini:

Não pode haver inocência numa relação negocial onde uma das partes estabelece os termos do contrato, fixa todas as suas cláusulas, e a outra (o consumidor), só tem a alternativa de aceitar o que foi disposto, de aderir a oferta. Evidencia-se que aí há um claro monopólio e sobreposição de benefícios, desaparecendo em absoluto a vontade real do contratante desfavorecido. (ALTERINI, 2014,p.125).

A metodologia de formulação dos contratos por adesão se expressa pela elaboração e imposição de cláusulas predispostas apresentadas num "contrato - formulário", fator que não se resume a uma mera forma de redação, vai mais além, representa a real determinação do conteúdo contratual imposto ao outro contratante, que diante de suas necessidades de consumo, sujeita-se e aceita o que foi proposto.

Assim, o contrato por adesão não é resultado de um consentimento livremente prestado pelas partes situadas num mesmo patamar de igualdade, como prega a "essência" e sentido da liberdade contratual, conforme vimos anteriormente. Na verdade representa uma imposição unilateral de vontade de uma das partes sobre a outra. Dessa forma, nessas condições, não se pode atribuir à adesão o valor de um real consentimento ou convergências de vontades, o que ocorre de fato é um assentimento, uma mera aceitação.

De certa maneira, assim é sedimentada a simbologia sobre as relações sociais e a dinâmica do capitalismo, que propõem a generalização do ato de consumir que, numa sociedade de consumo massificado, configura-se, também, pelas contratações por adesão, que se tornam elementos essenciais para sustentação dos preceitos capitalistas, que se baseiam de maneira substancial no consumo. É o que Marx chama de 
“Esfera da Circulação" (MARX, 1990, p. 47), como afirma Fernand Braudel:

A economia, à primeira vista, consiste em duas enormes zonas: a produção e o consumo, aqui tudo acaba e se destrói, ali tudo começa e recomeça....Uma sociedade não pode parar de produzir, tal como não pode parar de consumir. (BRAUDEL, 2005, p.72).

Em nossa sociedade capitalista contemporânea, também tratada como sociedade de consumo pela importância que o ato de consumir representa na sua dinâmica e estruturação, os contratos também ganham características específicas, caso do contrato por adesão.

Este tipo de contratação tornou-se basilar, indispensável e essencial, uma vez que viabiliza o uso-acesso-consumo de bens em escala universal, produzidos, porém, por um número reduzido de empresas que se expandem mundialmente nos territórios e mercados dos diferentes países, mas suas matrizes são, preponderantemente, das nações que controlam a indústria, as finanças, as tecnologias e também as mídias.

Essas empresas são as chamadas multinacionais, as donas do grande capital internacional e as que constituem um dos principais elementos do sistema econômico contemporâneo, uma vez que possibilitam e viabilizam o fornecimento e utilização de bens e serviços de consumo de maneira coletiva e homogênea.

Outro tema que merece destaque é a análise da natureza jurídica dos contratos por adesão, pois surge a questão de se seria ele um contrato. A discussão já existia desde 1905, quando Raymond Saleilles, esboça em sua obra sobre a declaração de vontade das relações jurídicas: "Se há o predomínio exclusivo de uma só vontade nas relações contratuais, atuando como uma vontade unilateral, deve ser excluído o caráter contratual dessas transações”. (SALEILLES, 1905, p. 229).

Esse debate ganhou força com a publicação, em 1974, da obra The Death of Contract (A morte do contrato) de Grant Guilmore, na qual tratou da ação demolidora dos novos tempos nos alicerces conceituais do contrato, sobretudo no princípio da autonomia da vontade, elemento basilar da teoria contratual clássica. 
Afirmou que o fenômeno da padronização das transações comerciais, decorrente de uma economia massificada (mass production), teria subvertido e aniquilado o princípio da liberdade contratual, transformando o contrato numa norma unilateral, imposta pelo contratante mais forte da relação negocial.

Se nos restringirmos a ideia de paridade e igualdade das partes nessa forma de contratar, de fato deveria ser entendido apenas como um ato unilateral onde a mera aceitação não constituiria um consentimento efetivo. Contudo, essa não é a melhor forma de tratar o assunto, pois não se pode negar a natureza contratual desse instituto jurídico, pois existe, mesmo que de maneira minorada a bilateralidade em sua formação.

O radicalismo não deve prevalecer, a discussão e construção mútua do conteúdo contratual não são pressupostos indeclináveis na configuração do contrato e, ao aderente, sempre vai existir a possibilidade de aceitar, ou não, a contratação.

$\mathrm{O}$ ato de aderir deve ser considerado como um fenômeno de consciência e vontade que, mesmo minorado e restringido, representa uma expressão e manifestação válida de vontade que outorga validade ao instrumento que deve, portanto, submeter-se aos mesmos pressupostos e requisitos de legitimação e validade das outras formas contratuais. Para finalizarmos este tópico, é necessário apontarmos as principais características que constituem o contrato por adesão, vejamos:

\subsection{AUSÊNCIA DE FASE PRÉ-NEGOCIAL}

É um elemento essencial do contrato por adesão a inexistência de uma negociação entre os contratantes (proponente e aderente), não existe uma discussão prévia acerca das cláusulas e do conteúdo contratual - se existisse desconfiguraria o formato da contratação em massa, que deve ser rígida e uniforme - restando apenas à outra parte a opção de aceitar inteiramente ou rejeitar a contratação, a vontade do aderente é manifestada pela mera adesão ao que foi proposto (imposto).

\subsection{CONSENTIMENTO}

O contrato por adesão deve seguir todos os requisitos de validade dos contratos, além de agente capaz, objeto lícito, possível, determinado ou determinável e forma prescrita ou não defesa em lei, requisitos de 
validade dos negócios jurídicos estipulados pelo artigo 104 do Código Civil brasileiro. Cientes que o contrato é formado e validado pelo acordo de vontades, é o consentimento outro requisito essencial na contratação, uma vez que é a expressão, a manifestação da vontade.

No caso dos contratos por adesão, o consentimento é dado pela simples aceitação da vontade manifestada pelo proponente, exigindo-se apenas a capacidade civil dos contratantes. Surge daí o questionamento da necessidade da análise do grau de efetivo entendimento das disposições contratuais para a validação do negócio.

Sabe-se que diante do grande volume negocial, da pressa cotidiana, da falta de atenção, da forma muitas vezes ilegível ou rebuscada, pela falta de conhecimento do consumidor, pelo mero fato de não dar importância ao contrato/ termo de adesão ou pelo não interesse em refletir sobre o que ele representa (processo advindo da alienação, que será tratada em momento oportuno), os contratos não são entendidos ou nem sequer são lidos pelo aderente, suscita-se então a validade desse consentimento.

Diante de toda essa discussão, o Código Civil do Brasil estabeleceu em seu artigo 423: "Quando houver no contrato de adesão cláusulas ambíguas ou contraditórias, dever-se-á adotar a interpretação mais favorável ao aderente", entendeu o legislador que, em muitos casos, a compreensão no ato de aderir não existe, pelo menos de forma total, determinando que a interpretação deva ser contra aquele que redigiu o instrumento de modo dúbio ou dificultoso, sendo essa determinação mais uma expressão do dirigismo contratual e da proteção à parte mais fraca da relação negocial, postura assumida de maneira clara pelo Sistema de Defesa do Consumidor, fortemente presente nos países latino americanos.

E essa postura estatal protecionista torna-se uma necessidade, em virtude da clara fragilidade de uma das partes contratantes e do prejuízo que essa debilidade representa para todo o sistema econômico e social. Nesse sentido, esclarece Joaquim de Souza Ribeiro:

A própria práxis negocial foi pondo a nu, em certas áreas da contratação, em especial as coletivas, que a autonomia privada, expressada pelo livre consentimento, deixados a si próprios, não mediavam satisfatoriamente determinados conflitos entre os agentes do tráfego jurídico - econômico. Também porque, e desde logo, uma incondicionada 
liberdade contratual, em todos os domínios, não se mostrou capaz de organizar eficientemente as relações de troca e de cooperação no mercado (RIBEIRO, 2007, p. 47).

Outra determinação protetiva e intervencionista é a estabelecida no artigo 46 do Código de Defesa do Consumidor do Brasil:

Os contratos que regulam as relações de consumo não obrigarão os consumidores, se não lhes for dada a oportunidade de tomar conhecimento prévio de seu conteúdo, ou se os respectivos instrumentos forem redigidos de modo a dificultar a compreensão de seu sentido e alcance.

Trata-se de uma norma que aborda o consentimento nas relações de consumo, determina a lei, a necessidade de conhecimento prévio do conteúdo contratual sob pena de falta de obrigatoriedade do acordo, e esse ponto é fundamental na busca do entendimento de como se validam essas contratações, pois o conteúdo contratual normalmente é apresentado ao consumidor, e isso cumpre com o que a lei determina e exige, mas que em verdade mascara uma efetiva aceitação e concordância com o que foi proposto.

Pois como não há a possibilidade de discussão ou alteração do que foi posto, nada muda em relação ao aderente, que tem apenas a possibilidade de concordar ou não contratar, é o que parte da doutrina anglo - americana denomina de "take it or leave it contracts", que podemos entender como tome-o ou deixe-o, em outras palavras, concorde ou não contrate, e numa sociedade onde o consumo assume papel tão relevante e direcionador, normalmente o consumidor concorda, e não questiona.

\subsection{INEXISTÊNCIADALIBERDADE CONTRATUAL}

É característica essencial do contrato por adesão a predisposição unilateral das cláusulas contratuais, cabe ao consumidor concordar com o proposto ou não contratar, extingui-se a liberdade contratual, a possibilidade de formulação bilateral dos termos do negócio.

É a forma mais latente de restrição da vontade do aderente, porém não é a única. A partir do momento que o contrato é aceito e firmado, a 
imposição da vontade do contratante mais forte, e por consequência as limitações da vontade do consumidor, prolongam-se durante todo o cumprimento da contratação.

Claro que existem todas as possibilidades jurídicas de revisão ou até mesmo anulação do contrato, baseadas na justiça contratual, estabelecidas de maneira clara em nosso ordenamento, mas até que o Poder Judiciário seja acionado, atue com seu poder de império e emita uma decisão favorável ao consumidor, até mesmo de maneira retroativa ao momento da contratação, prevalecem os ditames estabelecidos no texto do contrato.

Em outras palavras, nosso Direito atua de maneira eficaz na proteção do contratante/consumidor, vários dispositivos e diplomas legais, sobretudo o Código de Defesa do Consumidor, apresentam um arcabouço protetivo ao ente mais vulnerável na relação negocial, não se tratando rigorosamente do intuito de promover uma igualdade, mas sim uma igualação entre os contratantes.

Outorga um tratamento jurídico diferenciado a essas relações através da revisão dos acordos celebrados entre as partes, o Ordenamento Jurídico, com sua postura dirigente e protetiva, objetiva estabelecer um equilíbrio econômico das prestações, ato que implica na admissão da noção de desigualdade entre os sujeitos contratantes nas relações de consumo. Mas até o momento que exista efetivamente uma decisão judicial protetiva, vigoram as cláusulas impostas na contratação.

\section{DIALÉTICA: BREVES QUESTÕES}

Sem maiores ênfases nas questões ontológicas, o materialismo determina que o mundo fático, exterior ao sujeito, existe independente de sua consciência, de maneira que devemos entender a dialética não apenas como uma construção ou conceituação humana, mas como o próprio movimento natural da realidade, seja ela, ontologicamente falando, do mundo inorgânico, orgânico e/ou social.

Desta forma, devemos romper com o obstáculo epistemológico ${ }^{5}$ da falsa transparência, que propõe a simplificação demasiada dos conceitos jurídicos: o contrato é conceituado e classificado de maneira simplista e

5 Aqui tratamos especificamente da obra de Michel Miaille "Introdução Crítica ao Direito", que apresenta esses obstáculos como entraves e impedimentos à construção do saber científico. 
com pouca crítica e profundidade, alicerçado na comodidade da superficialidade, sem buscar sua verdadeira estrutura dialética e sem vínculo com a realidade social, econômica e capitalista.

Precisamos entender e compreender o contrato como uma síntese de relações sociais e humanas, de interesses opostos e contraditórios, e termos esse entendimento é essencial para a real compreensão de nossa sociedade pois, nas palavras de Baudrillard:

Na prática cotidiana de nossa sociedade, os resultados e benefícios do consumo não se vivem como frutos do trabalho ou dos processos de produção e negociação; vivemse como milagres. (BAUDRILLARD, 1995, p.22).

Esse processo de questionamento torna-se fundamental porque se não for problematizando, expressa somente a noção que o contrato por adesão representa um elemento que fortalece os/as consumidores/as no sentido de possibilitar a concretização de suas necessidades e desejos de consumo, além de passar a ideia que expressa uma relação de paridade e isonomia entre os contratantes.

Contudo, o monopólio do conteúdo do contrato, das cláusulas, está com a parte contratante mais forte, a do capital, a do empresariado (industrial, comercial, financeiro e midiático). Os/as consumidores/as, a outra parte da relação, se não aceitam, não aderem, não podem usufruir o bem/mercadoria. Dessa maneira, o contrato revela-se como uma expressão de relações assimétricas e desiguais.

Nesse processo, o contrato por adesão atua como um instrumento da lógica do lucro capitalista, utilizado pelo sistema econômico para estimular, estruturar, possibilitar e direcionar as lucrativas práticas de consumo em suas várias vertentes.

Para compreender o contrato por adesão, nesse desafio desde uma perspectiva de totalidade, deve ser analisado sob a ótica da dialética de sua construção, como um elemento econômico, social e também simbólico, cristalizador das forças de trabalho humano, construído e constituído por contradições e interesses que vão além dos classicamente apresentados como segurança jurídica, facilitador de negociações e provedor de uma "igualação" negocial e social. 


\section{CONSIDERAÇÕES FINAIS}

Devemos ter a consciência que a verdade absoluta não existe e que o conhecimento científico está em constante processo de apreensão, compreensão, construção e significação da realidade e da pluralidade que o constitui.

Não pretendemos, portanto, encerrar aqui as discussões acerca do tema e problemas em análise, nem oferecer definições concluídas, o objetivo foi mostrar que as questões aqui apresentadas são relevantes e merecem ser discutidas, debatidas e repensadas. Suas múltiplas determinações e mediações precisam ser conhecidas e compreendidas num processo crítico e de questionamento e mudança das práticas de consumo e dos conceitos que são impostos e de certa forma, internalizados e aceitos por nós.

Diante dos enunciados e perspectivas apresentados, fica claro que o contrato por adesão mostra-se como elemento fundamental na sociedade contemporânea, é fruto e resultado do desenvolvimento e dos anseios sociais, produtivos e econômicos, atua como um elemento viável e necessário que possibilita e permite o intercâmbio de bens, valores e serviços, estimulando a cooperação e promovendo a maximização do bem estar dos consumidores ${ }^{6}$.

Mas como é um elemento multifacetado, também representa uma relação de disparidade entre os contratantes, é preciso termos a consciência que esse modo de contratar também apresenta uma face reversa e dicotômica, pois dá a falsa ideia de que é um elemento que simplesmente fortalece o consumidor no sentido de possibilitar a concretização de suas necessidades e desejos de consumo, quando na realidade é um instrumento utilizado pelo sistema econômico para estimular e direcionar o consumo.

Precisamos ir além da simples aparência, das manifestações imediatas da realidade, dos processos sociais e suas relações. Devemos observar, questionar e investigar a complexidade dessas relações sociais e históricas de forma mais ampla, crítica e profunda, pois diante de uma sociedade tão célere e ávida por novidades e transformações, novas possibilidades e caminhos nos são apresentados a todo momento.

6 Embora não seja pacífico na doutrina, neste trabalho, aceitar que as contratações por adesão são restritas às relações de consumo. 
Devemos contemplar, apreender e investigar as múltiplas nuances da realidade, que muitas vezes é configurada por relações sociais, ideias e visões de mundo (ideologias) conflituosas, sendo a contradição um componente dessa confluência, que merece ser identificada e compreendida também sob uma perspectiva dialética, crítica e questionadora.

\section{REFERÊNCIAS BIBLIOGRÁFICAS}

ALTERINI, Atilio Aníbal. (2014) Contratos Civiles, comerciales, de consumo. Teoría General. 2.ed. Buenos Aires: Editora Abeledo Perrot

BAUDRILLARD, Jean. (1995) A sociedade de consumo. Lisboa: Editora Edições 70

BAUMAN, Zygmunt. (2009) A sociedade individualizada. São Paulo: Editora Zahar (2003) Comunidade: a busca por segurança no mundo atual. Rio de Janeiro: Editora Zahar

BOBBIO, Norberto. (2005) Teoria da Norma Jurídica. Tradução: Denise Agostinetti. São Paulo: Editora Forense

BONAVIDES, Paulo. (1972) Do estado liberal ao estado social. 3.ed. Rio de Janeiro: Editora Fundação Getúlio Vargas

BOURDIEU, Pierre. (1984). A economia das trocas simbólicas. São Paulo: Editora Perspectiva.

BRAUDEL, Fernand. (2005) Civilização material, econômica e capitalismo - Século XV-XVIII. São Paulo: Editora Martins Fontes

BUSTAMANTE, Laura Pérez. (2008) Los Derechos de la Sustentabilidad: Desarrollo, consumo y ambiente. Buenos Aires: Editora Colihue

CANCLINI, N. G. (2010) Consumidores e Cidadãos. 8. ed. Rio de Janeiro: Editora da UFRJ

CÁRCOVA, Carlos Maria. (2012) Las teorías jurídicas post positivistas. Buenos Aires: Editora Abeledo Perrot, 2.ed 
DOUGLAS,M.; ISHERWOOD,B. (2010) El mundo de los bienes. Hacia una antropologia

del consumo. Ciudad de México: Editora Grijalbo

GEHLEN, Frank. (2005) Perspectivas Filosóficas do Direito. 2.ed. São Paulo: Editora Revista dos Tribunais

GHERSI, Carlos. (2011) Manual de los Derechos de Usuarios y Consumidores. Buenos Aires: Editora La Ley

HALL, Stuart. (2006) A identidade cultural na pós-modernidade. Rio de Janeiro: Editora DP \& A

IHERING, Rudolf von. (2003) A luta pelo Direito. São Paulo: Martin Claret

KUNZ, Ana Elena Margarita, (2013) CARDINAUX, Nancy Susana. Investigar en Derecho. 1.ed. Buenos Aires: Departamento de Publicaciones, Facultad de Derecho. Universidad de Buenos Aires

LIPOVETSKY, Gilles.(1989) Império do efêmero: a moda e seu destino nas sociedades modernas. Tradução de Maria Lúcia Machado. São Paulo: Editora Companhia das Letras

LISBOA, Roberto Senise. (2004) Contratos difusos e coletivos: consumidor, meio ambiente, trabalho, locação e autor. 6.ed. São Paulo: revista dos Tribunais

LORENZETTI, Ricardo Luis. (2010) Tratado de los contratos. Parte general.2.ed. Buenos Aires: Rubinzal-Culzoni

MANDELBAUM, Renata. (2008) Contratos de adesão e contratos de consumo. São Paulo: Editora Revista dos Tribunais

MANDEL, Ernest. (1968) A formação do pensamento econômico de Karl Marx. Rio de Janeiro: Editora Zahar ,(1982) Capitalismo Tardio. São Paulo: Editora Abril Cultural.

MARQUES, Cláudia Lima. (2012) Contratos no Código de defesa do Consumidor. 5.ed. São Paulo: Editora Revista dos Tribunais 
MARX, Karl. (1985) Formações Econômicas Pré-capitalistas. 4.ed. Rio de Janeiro: Editora Paz e Terra , Karl. (2010) O Capital. 8.ed. São Paulo: Editora La Paz , Karl. (1990) Introducción General a la Crítica de la Economía Política. Medellín: Editora Prisma

McCRACKEN, Grant. (2004) Cultura e Consumo. Rio de Janeiro: Editora Mauad

MIAILLE, Michel. (2012) Introdução Crítica ao Direito. 2.ed. São Paulo. Editora dos Tribunais

MORI, Giorgio. (2000) La Revolución Industrial. Barcelona: Editora Crítica

NETO, Guilherme Fernandes. (2014) O abuso do direito no Código de Defesa do Consumidor: cláusulas, práticas e publicidades abusivas. Brasília: Editora Brasília Jurídica

NOZAKI, Haiime T. (2008) A produção em Marx e a utilização do método materialista dialético para sua análise. Brasília: EditoraTrabalho necessário, ano $6, \mathrm{~N}^{\mathrm{0}} 6$

PACHUKANIS, Evgeny Bronislanovich. (1989) A Teoria Geral do Direito e o Marxismo. Tradução: Paulo Bessa. Rio de Janeiro: Editora Renovar

PINTO, João Bosco Guedes. (2014) Metodologia, teoria do conhecimento e pesquisa-ação. Organização: Laura Susana DuqueArrazola, Michel Jean Marie Thiollent. Belém: Editora Ciências Sociais Aplicadas

RABINOVICH-BERKMAN, Ricardo D. (2010) Principios Generales del Derecho Latinoamericano. 1.ed. Buenos Aires: Editora Astrea.

RIBEIRO, Joaquim de Souza. (2007) Direito dos Contratos - Estudos. Coimbra: Editora Coimbra

ROCHA, Maria Eduarda da Mota. (2010) A Nova Retórica do Capital: a Publicidade Brasileira em Tempos Neoliberais. São Paulo: Editora da Universidade de São Paulo 
RUBIN, Isaac Illich. (1980) Ensayo sobre la teoria marxista del valor. Ciudad de Mexico: Editora Siglo XXI

RUIZ, Roberto Martínez. (2012) Contratos - temas actuales. Buenos Aires: Editora Abeledo - Perrot

SALEILLES, Raymond. (1905) La Déclaration de Volunté. Tradução: Stella Doranni. Paris: Editora Journals

STOUDER, Eduardo. (2011) Análisis Económico del Derecho. Buenos Aires: Editora Abeledo-Perrot

TASCNER, Gisela. (1995) Proteção do Consumidor: um estudo comparativo internacional. São Paulo: Escola de Administração de Empresas de São Paulo/ Fundação Getúlio Vargas - Relatório 1

TAUSSIG, Michael. (2010) O diabo e o fetichismo da mercadoria na América do Sul - Tradução: Priscila Santos da Costa. São Paulo: Editora Unesp

TINANT, Eduardo Luis. (2011) Bioética jurídica, dignidad de la persona y derechos humanos. Buenos Aires: Editora Dunken, 2. Ed

ZACHETO, Etorino. (1998) Comunicación y actitud crítica. Tucumán: Editora Paulianas

\section{Legislação:}

\section{ARGENTINA}

Código Civil da la República Argentina. Buenos Aires: Abeledo Perrot, 2012.

Ley de Defensa del Consumidor. Buenos Aires: La Ley, 2012.

\section{BRASIL}

Código Civil da República Federativa do Brasil. São Paulo: Rideel, 2012. 
Código de Defesa do Consumidor. São Paulo: Saraiva, 2012. COLÔMBIA

Estatuto del Consumidor. Bogotá(Ley 1.480/2011), 2013. 